\title{
Radiologic Health
}

National Cancer Institute

\section{Source}

National Cancer Institute. Radiologic Health. NCI Thesaurus. Code C17058.

The study of the health effects of radiation, with an emphasis on protecting the public, radiation workers, and the environment, and on establishing standards for radiation exposure. 